\title{
Gestational Trophoblastic Neoplasia after Ectopic Molar Pregnancy: Clinical, Diagnostic, and Therapeutic Aspects
}

\section{Neoplasia trofoblástica gestacional após gestação molar ectópica: aspectos clínicos, diagnósticos e terapêuticos}

\author{
Consuelo Lozoya López ${ }^{1}$ Vania Gloria Silami Lopes ${ }^{1}$ Fabiana Rodrigues Resende ${ }^{1}$ Jessica Lara Steim ${ }^{1}$ \\ Lilian Padrón ${ }^{1,2}$ Sue Yazaki Sun ${ }^{3}$ Edward Araujo Júnior ${ }^{3}$ Antonio Braga1,2,4 \\ ${ }^{1}$ Department of Pathology, Universidade Federal Fluminense, Niterói, \\ RJ, Brazil \\ 2 Rio de Janeiro Trophoblastic Disease Center, Associação Brasileira de \\ Doença Trofoblástica Gestacional, Rio de Janeiro, RJ, Brazil

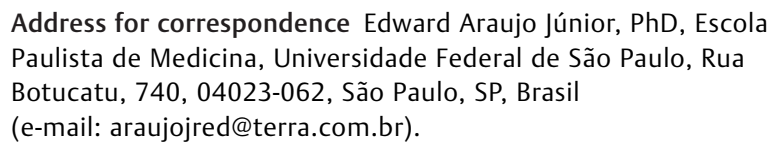

${ }^{3}$ Department of Obstetrics, Escola Paulista de Medicina, Universidade Federal de São Paulo, São Paulo, SP, Brazil

${ }^{4}$ Department of Gynecology and Obstetrics, Universidade Federal do Rio de Janeiro, Rio de Janeiro, RJ, Brazil

Rev Bras Ginecol Obstet 2018;40:294-299.

\section{Abstract \\ Keywords \\ - ectopic pregnancy \\ - hydatidiform mole \\ - gestational trophoblastic neoplasia \\ - pathology \\ Resumo \\ Palavras-chave \\ - gravidez ectópica \\ - mola hidatiforme \\ - neoplasia trofoblástica gestacional \\ - patologia}

This report presents the case of a patient with gestational trophoblastic neoplasia after a partial hydatidiform mole formed in the Fallopian tube. Ectopic molar pregnancy is a rare condition, with an estimated incidence of 1 in every 20,000 to 100,000 pregnancies; less than 300 cases of it have been reported in the Western literature. The present report is important because it presents current diagnostic criteria for this rare condition, which has been incorrectly diagnosed in the past, not only morphologically but also immunohistochemically. It also draws the attention of obstetricians to the occurrence of ectopic molar pregnancy, which tends to progress to Fallopian tube rupture more often than in cases of ectopic non-molar pregnancy. Progression to gestational trophoblastic neoplasia ensures that patients with ectopic molar pregnancy must undergo postmolar monitoring, which must be just as thorough as that of patients with intrauterine hydatidiform moles, even if chemotherapy results in high cure rates.

Esse relato apresenta um caso de neoplasia trofoblástica gestacional após mola hidatiforme parcial ocorrida na tuba uterina. Trata-se de uma associação rara, cuja incidência estima-se de 1 em cada 20.000 a 100.000 gestações, havendo menos de 300 casos apresentados na literatura ocidental. O tema é importante porque apresenta critérios diagnósticos atuais para essa ocorrência incomum, que vinha sendo diagnosticada equivocadamente, não apenas sob o ponto de vista morfológico, como também imunohistoquímico. Da mesma forma, alerta o obstetra para a ocorrência da gravidez molar ectópica, que tende a evoluir com rotura tubária mais frequentemente do que os casos de gravidez ectópica não molar. Por fim, a evolução do caso para received

January 17, 2018

accepted

April 4, 2018

published online

May 16, 2018
DOI https://doi.org/

10.1055/s-0038-1653976.

ISSN 0100-7203.
Copyright $(2018$ by Thieme Revinter

Publicações Ltda, Rio de Janeiro, Brazil

License terms

c) $(1) \$$ 
neoplasia trofoblástica gestacional impõe às pacientes com gravidez ectópica molar a necessidade de seguimento pós-molar tão rigoroso quanto nos casos de mola hidatiforme intrauterina, ainda que o tratamento quimioterápico determine elevadas taxas de cura.

\section{Introduction}

Molar pregnancy, which is a benign form of gestational trophoblastic disease (GTD), is an anomaly that affects 1 in every 200 to 400 pregnancies in Brazilian women; this is a 5 to 10 -fold higher incidence than that found in the United States of America and Europe. ${ }^{1-3}$ This gestational disease, which has a predilection for the extremities of those in reproductive age range, ${ }^{4}$ arises due to abnormal fertilization and appears in two different forms: complete hydatidiform mole (CHM) and partial hydatidiform mole (PHM). ${ }^{2}$ While a CHM is characterized by androgenetic diploidy, a PHM is characterized by digynic triploidy. ${ }^{5}$

In addition to genetic differences, a CHM can progress to gestational trophoblastic neoplasia (GTN) 15 to $25 \%$ of the time, while a PHM progresses to GTN only 1 to $5 \%$ of the time. ${ }^{6}$ The largest epidemiological study conducted in Brazil observed progression to GTN in $24.6 \%$ of the patients with CHM and in $7.6 \%$ of the patients with PHM. $^{7}$

Ectopic molar pregnancy (EMP) rarely occurs and has an estimated incidence of 1 in every 20,000-100,000 pregnancies. $^{8-11}$ A 15-year review of the Sheffield Trophoblastic Disease Center case study showed that EMP is even rarer, affecting 1.5 in every 1 million births in the United Kingdom. ${ }^{12}$ Reviews of the EMP case series using strict criteria described for diagnosing intrauterine molar pregnancy have shown that this entity was overdiagnosed, as only 6 to $15 \%$ of patients originally described as having EMP has that diagnosis confirmed after performing careful diagnostic review. ${ }^{13,14}$

Unlike ectopic non-molar pregnancy, in which the Fallopian tube is affected in $98 \%$ of the cases, in a review of 31 cases of EMP, there was evidence of the involvement of the Fallopian tube in $61 \%$ of the cases, ovaries in $16 \%$, uterine horn in $10 \%$, peritoneum in $6 \%$, cervix in $3 \%$, and C-section scar in $3 \%{ }^{15}$ Regarding the prognosis of patients with EMP, it appears to be similar to that of patients with intrauterine molar pregnancy, ${ }^{14,16}$ and cases in which chemotherapy had to be administered to treat postmolar GTN are uncommon., 914

The present clinical report aimed to present a rare case of GTN after EMP, highlighting its clinical, diagnostic, and therapeutic aspects.

\section{Case Description}

A 34-year-old patient in her second pregnancy and who had a previous miscarriage visited the Emergency Obstetric Unit with complaints of abdominal pain, vomiting, and vaginal bleeding.

The patient was in the $8^{\text {th }}$ week after the missed menstrual period and had a reactive immunological pregnancy test, but she had not yet undergone obstetric ultrasound. From the beginning of her pregnancy, she had experienced intermittent vaginal bleeding lasting for 6 weeks and uncontrollable vomiting, and she lost $10 \mathrm{~kg}$ in the last 3 months. She reported that in the last 48 hours, she had begun to experience sharp abdominal pain in the hypogastric region, radiating to the back, with an intensity of $8 / 10$, which worsened with palpation and improved with rest.

During a clinical examination, the patient exhibited a facial expression of pain, with a blood pressure of $100 \times 70 \mathrm{~mm} \mathrm{Hg}$, a heart rate of $90 \mathrm{bpm}$, a respiratory rate of 18 breaths per minute, axillary temperature of $37^{\circ}$ $\mathrm{C}$, and rectal temperature of $37.5^{\circ} \mathrm{C}$. A speculum examination detected a closed internal orifice with the presence of slight vaginal bleeding. Upon performing a pelvic examination, the cervix was found to be softened, with a closed internal orifice, intrapelvic uterus, and a palpable and extremely painful adnexal mass in the left adnexus.

The patient underwent transvaginal ultrasound; the uterus was found to measure $110 \times 89 \times 80 \mathrm{~mm}$, and there was a trilaminar, thickened, and homogeneous endometrium. A paraovarian mass was visualized in the left adnexus; it was $65 \times 40 \times 35 \mathrm{~mm}$ in size, filled with amorphous echoes, and avascular in the color Doppler image, suggesting EMP in the left Fallopian tube (-Fig. 1).

With this diagnostic suspicion, the patient was referred to the Centro de Doenças Trofoblásticas do Rio de Janeiro. A quantitative human chorionic gonadotropin (hCG) test had a result of $12,893 \mathrm{IU} / \mathrm{L}$. The patient underwent exploratory laparotomy with a Pfannenstiel incision; moderate hemoperitoneum was found, with evidence of a mass in the left Fallopian tube, with a slight ruptured area (-Fig. 2). Unilateral salpingectomy was performed, with the macroscopic evaluation of the material from the left Fallopian tube suggestive of a hydatidiform mole (-Fig. 3 ).

The material was sent for an anatomic-pathologic examination. On performing a histopathologic examination, microscopy revealed that the Fallopian tube was filled with chorionic villi of different sizes, showing central cisterns and trophoblastic hyperplasia with moderate atypia as well as ovular membranes and erythroblasts in villous vessels. A predominantly acute inflammatory reaction and bleeding areas in the tubal parietal region were observed ( - Fig. 4A and B). The immunohistochemical markers p57, p63, and ki67 were investigated. The p63 immunolabeling revealed moderately positive labeling in the lining of the trophoblasts (-Fig. 4C and D), while Ki67 immunolabeling revealed intense labeling (-Fig. $\mathbf{4 E}$ and F). Positive labeling in the villous stroma, cytotrophoblast, and maternal decidua were revealed by p57 immunolabeling ( - Fig. $\mathbf{4 G}$ and $\mathbf{H}$ ). In view of 

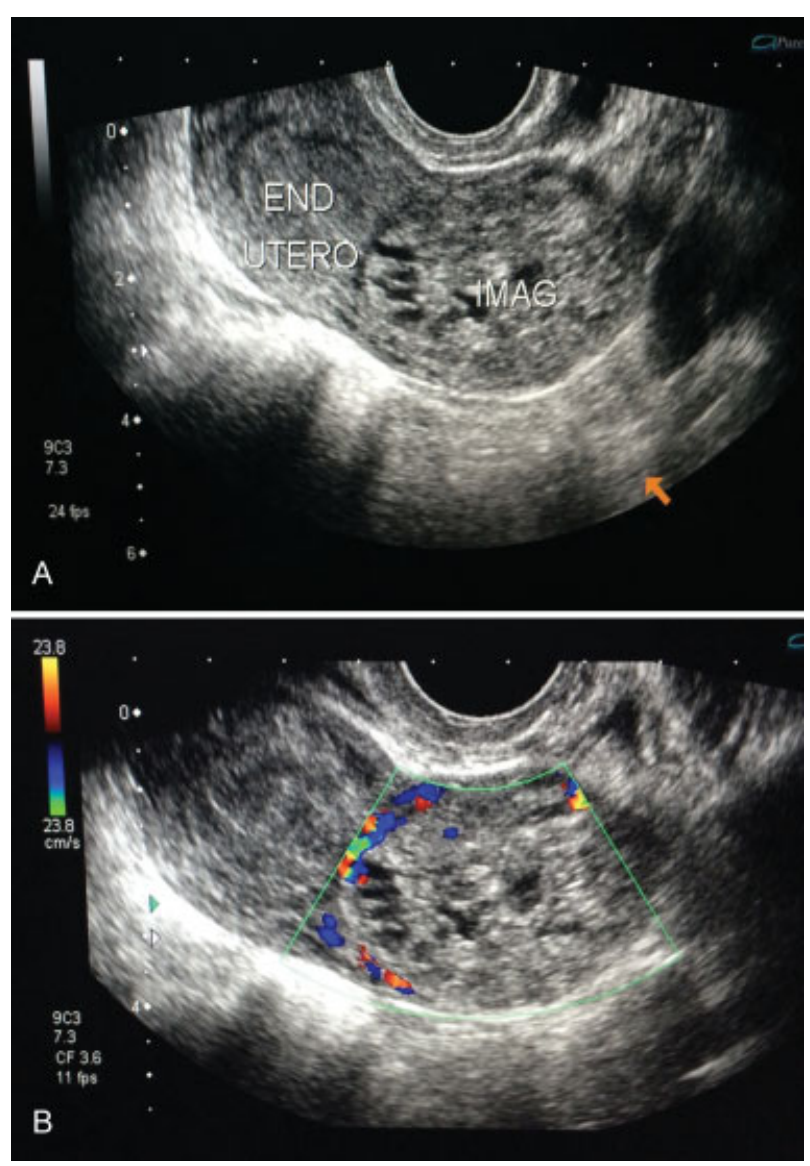

Fig. 1 (A) Transvaginal ultrasound showing a heterogeneous paraovarian adnexal mass; it was $65 \times 40 \times 35 \mathrm{~mm}$ in size and filled with amorphous, anechoic, and multicystic echoes. (B) The color Doppler image provided evidence that the adnexal mass did not have exuberant vascularization.

the anatomic-pathologic findings, the diagnosis was compatible with tubal ectopic PHM.

The patient was discharged 2 days after surgery, with oral hormonal contraception recommended as well as instructions to return for a postsurgical visit and postmolar pregnancy follow-up. During hormonal surveillance (-Fig. 5), elevated hCG levels were detected, characterizing the diagnosis of postmolar GTN, according to the International Federation of Gynecology and Obstetrics $2000 .{ }^{17}$ After GTN staging, with normal chest X-ray images and pelvic/transvaginal ultrasound results without abnormalities, the GTN was classified as stage I: 1 .

Chemotherapy with $1 \mathrm{mg} / \mathrm{kg}$ intramuscular methotrexate (MTX) was initiated on days 1, 3, 5, and 7, with $15 \mathrm{mg}$ folinic acid rescue therapy (citrovorum factor [CF]) orally administered on days $2,4,6$, and 8 (MTX/CF). The treatment was well tolerated, and the patient's only complaint was dry eyes (treated with artificial tears) and oral mucositis in the last chemotherapy cycle (treated with a mouthwash solution containing $150 \mathrm{~mL}$ of benzydamine hydrochloride $+25 \mathrm{~mL}$ of nystatin solution, vitamin E 5 capsules, and $20 \mathrm{~mL}$ of $2 \%$ lidocaine without a vasoconstrictor; $10 \mathrm{~mL}$ of this mixture were diluted in $10 \mathrm{~mL}$ of cold $0.9 \%$ saline and used as a

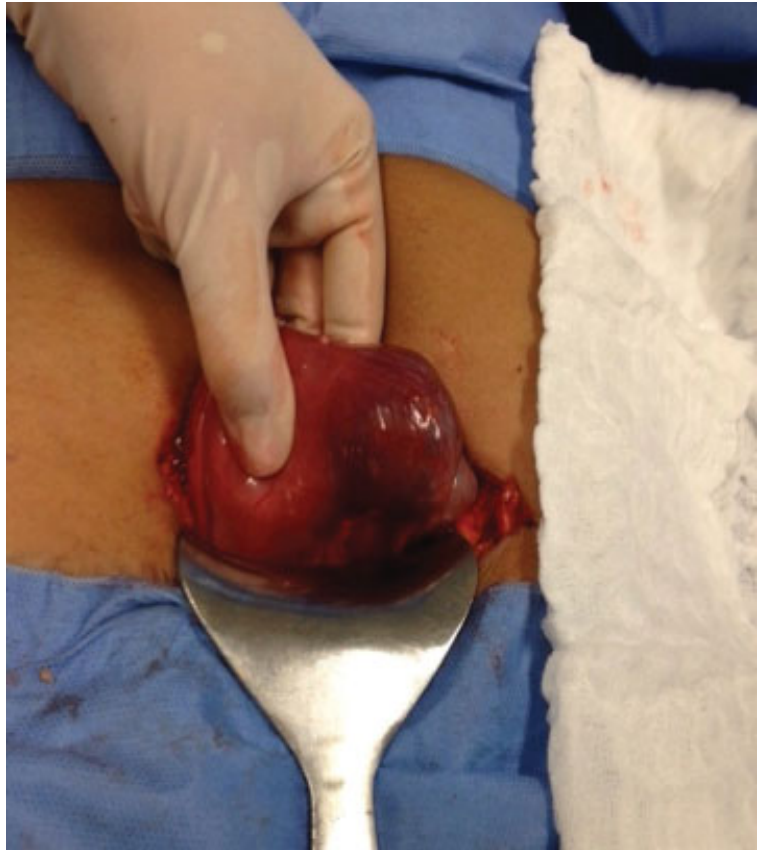

Fig. 2 Exploratory laparotomy via a Pfannenstiel incision with evidence in the abdominal cavity of a softened uterus with a burgundycolored tubal mass on the left measuring $\sim 7.0 \mathrm{~cm}$ and accompanied by hemoperitoneum, which are suggestive of ectopic pregnancy.

mouthwash every 4 hours). After 6 cycles of MTX/CF, the patient achieved remission and was further treated with three consolidation cycles of MTX/CF; at 24 months, the patient is still in sustained remission.

\section{Discussion}

The first report on EMP was written by Otto in $1871 .{ }^{18}$ Less than 300 cases of EMP have been reported over the past 150 years, showing the rarity of the association of this double obstetric complication. ${ }^{9-11}$ In addition, many of these cases initially reported as EMP were reassessed and later

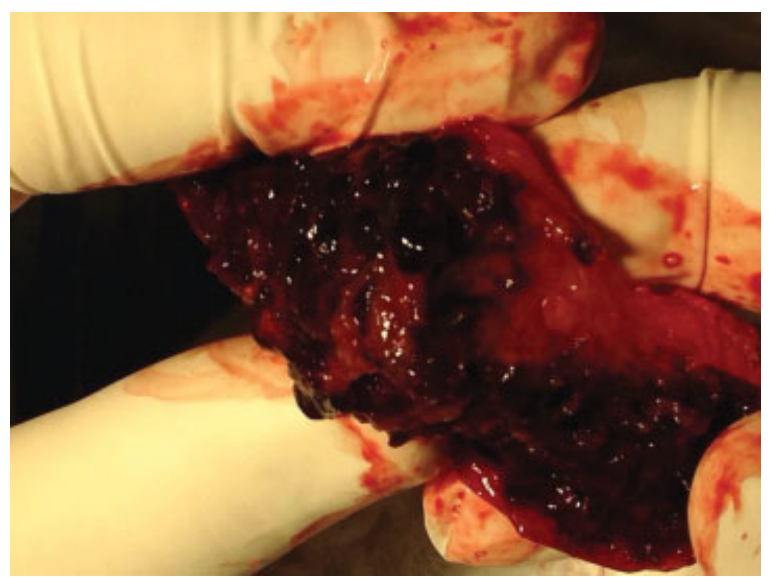

Fig. 3 Macroscopic view of placental material filled with small hydropic vesicles, suggestive of a hydatidiform mole in the Fallopian tube. 


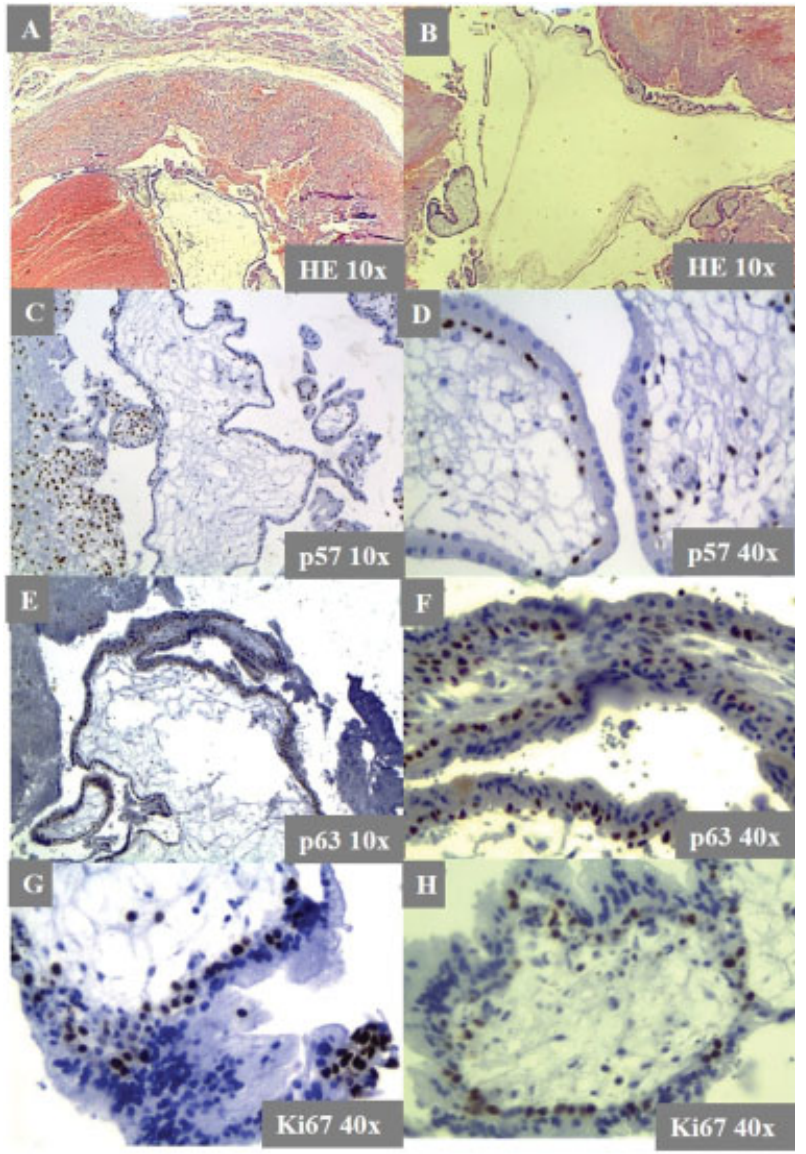

Fig. 4 Anatomic-pathologic examination of the material removed from the left Fallopian tube. In parts $A$ and $B$, it is possible to observe chorionic villi, with central cisterns, exhibiting trophoblast hyperplasia with moderate atypia, in addition to ovular membranes, a predominantly acute inflammatory reaction, bleeding areas in the tubal parietal region, and erythroblasts in villous vessels $(H E, 10 \times)$. In parts $C$ and $D$, the immunohistochemical evaluation results with p63 immunolabeling (moderately positive labeling on the trophoblast lining) can be seen (clone kp10/SP 118), 1:400 dilution, (Dako Corporation, Carpinteria, CA, USA). Isotope: IgG; antigenic reactivation: citrate $\mathrm{pH} 6.0$; overnight incubation $6^{\circ} \mathrm{C}$ ). In parts $\mathrm{E}$ and $\mathrm{F}$, immunohistochemical evaluation results with $\mathrm{Ki} 67$ immunolabeling (intense positive labeling on the trophoblast lining) can be seen (clone BC4A4, 1:900 dilution, [Dako Corporation, Carpinteria, CA, USA]. Isotope: IgG; antigenic reactivation: citrate $\mathrm{pH} 6.0$; overnight incubation $6^{\circ} \mathrm{C}$ ). In parts $\mathrm{G}$ and $\mathrm{H}$, the immunohistochemical evaluation results with p57 immunolabeling (positive labeling in the villous stroma, cytotrophoblast, and maternal decidua) can be seen (clone MIB 1, 1:100 dilution, [Dako Corporation, Carpinteria, CA, USA]. Isotope: IgG; antigenic reactivation: citrate $\mathrm{pH} 6.0$; overnight incubation $\left.6^{\circ} \mathrm{C}\right)$.

diagnosed as nonmolar pregnancy, with marked villous hydrops. ${ }^{13,14}$

The difficulty in correctly diagnosing EMP occurs because morphological abnormalities found during tubal pregnancy appear earlier than those seen in the trophoblastic tissue of miscarriages, at least in later cases. In ectopic pregnancy cases, it is possible to observe exuberant extravillous trophoblastic proliferation that is associated with apparent local invasion of surrounding tissues by trophoblasts, caus-

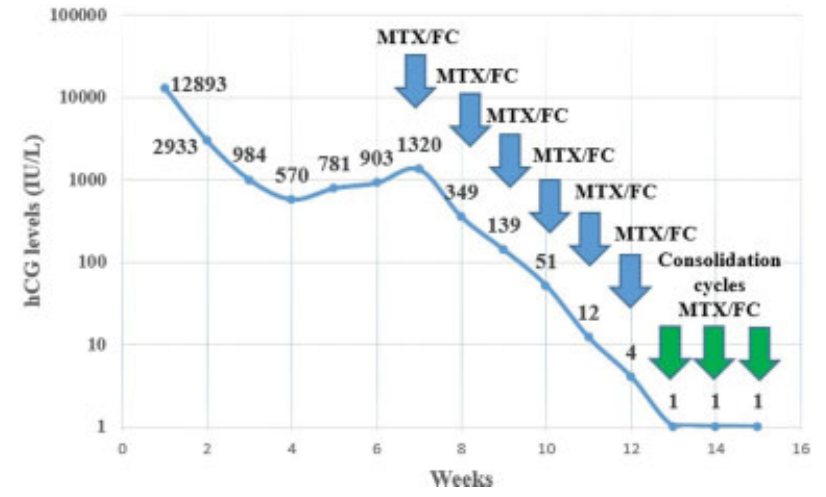

Fig. 5 Chart showing postmolar monitoring with hormonal surveillance and with periodic doses of hCG as well as chemotherapeutic treatment of the postmolar gestational trophoblastic neoplasia.

ing an EMP diagnosis to be incorrectly made. The morphological criteria for the correct diagnosis of EMP are the same as those used to characterize a intrauterine hydatidiform mole, notably the presence of definite, abnormal, nonpolar, trophoblast proliferation that is circumferential in nature, usually presenting with a vacuolated phenotype and that may be associated with sheets of pleomorphic extravillous trophoblast fragments. ${ }^{14,16}$ It is worth noting that there are significant phenotypic changes in hydatidiform moles, now mainly diagnosed in the first trimester, ${ }^{19}$ prompting pathologists to double their attention. ${ }^{20}$

The current histopathological criteria used to confirm CHM are hydropic villi with sizeable cisterns characterized by acellular central fluid spaces, hyperplasia, and marked atypias of the trophoblastic epithelium and, often, avascular villi. The presence of embryonic and adnexal elements can be found in PHM, with hydropic villi together with occasional cisterns, moderate trophoblastic hyperplasia, slight atypia, and normal villi containing vessels, sometimes with fetal red blood cells. However, there is significant inter- and intra-observer diagnostic variability, even among specialized pathologists. ${ }^{21}$

Immunohistochemical markers, such as p57, p63, and $\mathrm{K}_{\mathrm{i}^{-}}$ 67 , have been used to promote the correct diagnosis of molar pregnancy, and thereby recognize EMP, and to differentiate between a CHM and a PHM. ${ }^{22}$ The $\mathrm{p} 57$ marker is a protein that is formed from the imprinting of a paternal gene that expresses the maternal allele and is very effective in distinguishing a CHM from a PHM. While a CHM does not express this marker, as it only contains the paternal genome due to its androgenetic constitution, PHMs and cases of non-molar miscarriages express this marker diffusely. ${ }^{23}$ However, this marker has the limitation that it does not distinguish a PHM from cases of non-molar pregnancies; in such cases, markers such as p63 and Ki67, which are used as markers of cell proliferation, are necessary to make this differentiation. ${ }^{24}$ In PHM, $\mathrm{K}_{\mathrm{i}}-67$ expresses the nuclei of cytotrophoblast and intermediate trophoblast cells intensely that signals high cellular activity and differs from cases of hydropic abortion, where this marker is weakly immunoreactive. ${ }^{22}$ On the other hand, p63 is a tumor suppressor gene that exhibits increased expression in the nuclei of trophoblastic epithelial cells of 
CHMs and PHMs but is absent in cases of hydropic abortion. ${ }^{22}$ The case presented in the current report fulfills all morphological and immunohistochemical criteria of a PHM as tubal ectopic pregnancy.

Although the morphological description shows trophoblastic invasion in the Fallopian tube, we did not describe the presence of an invasive mole. ${ }^{14}$ The reasons for this are as follows. First, this terminology refers to a form of GTN that should only be applied to uterine neoplasia, in which there is a rise in hCG levels in the presence of transvaginal bleeding. Second, there is no maternal decidua in the Fallopian tube, so all histopathological findings of EMP will exhibit trophoblastic invasion locally to the superficial surrounding tissue, without necessarily indicating the present an invasive mole or even GTN, which, by definition, requires chemotherapy.

The anatomic-pathologic evaluation of all material obtained from the surgical treatment of cases of ectopic pregnancy is essential for the diagnosis of EMP because the clinical presentation of these two entities is very similar. Not even the high levels of hCG usually found in cases of molar pregnancy occur in EMP, as implantation in the uterine tube might preclude adequate vascularization and lead to lower hCG levels in cases of EMP than in the case of an intrauterine hydatidiform mole and as seen in the case presented here but similar to cases of non-molar ectopic pregnancy. $^{8}$

It is essential that the early ultrasound investigation of cases of pregnancy determines the location of the egg. The reason for this is that although EMP is generally diagnosed in the $8^{\text {th }}$ week of pregnancy, which not too distant from the mean diagnostic time in cases of non-molar ectopic pregnancy, ${ }^{25}$ the rate of rupture and hemoperitoneum in cases of EMP is $67 \%{ }^{15}$ while it is reported to be between 25 and $30 \%$ in cases of non-molar ectopic pregnancy. ${ }^{26}$ This may be due to the higher invasive ability of trophoblasts in cases of GTD than in cases of normal pregnancy. ${ }^{15}$ Therefore, an early diagnosis of ectopic pregnancy, performed by ultrasound, may prevent the occurrence of Fallopian tube rupture, which determines an important scenario of a near miss among Brazilian women. ${ }^{27}$ In addition, ultrasound can find clear signs of molar pregnancy in the adnexal mass, such as a tubal mass of variable echogenicity (although most hydatidiform moles are echogenic), with multiple, small, diffusely distributed vesicles with a "snowstorm-," "bunch-of-grape-," or "granular-" like appearance, ranging from $1 \mathrm{~mm}$ to $30 \mathrm{~mm}$ in size and representing hyperplastic and hydropic villi. 28 Transvaginal ultrasound does not have the same sensitivity for diagnosing EMP as it does for detecting the presence of intrauterine hydatidiform moles. This is not only because EMP sometimes has an inconclusive morphology but also because it is an early gestational anomaly, usually progressing with tubal rupture before the classic appearance of a hydatidiform mole can occur. Where appropriate, magnetic resonance imaging can be used when EMP is suspected. ${ }^{15}$

When EMP is suspected in the Fallopian tube, surgical treatment is indicated. Although there is no specific study, the laparoscopic approach is preferred. However, while salpingotomy is preferred in cases of non-molar ectopic pregnancy, when EMP is suspected, medical professionals have shown a preference for performing salpingectomy, avoiding the possibility of leaving trophoblastic material in the remaining tube..$^{9-11,13,14,25,29}$ We must insist that because the clinical and ultrasonographic findings of EMP can be non-specific and simulate non-molar ectopic pregnancy, it is extremely important to submit the material obtained during surgery for a histopathological and immunohistochemical study for making an accurate diagnosis. ${ }^{24}$

However, as mentioned above, as EMP may mimic nonmolar ectopic pregnancy situations, we must consider that some cases of EMP can be conservatively managed and observe the patient's progress and administer periodic doses of hCG or MTX. In these cases, where there is no histopathological diagnosis of EMP, hCG monitoring, which is already performed, is essential, and patients in whom hCG levels are elevated are successfully treated with MTX, which is the first line of treatment for cases of postmolar GTN. ${ }^{14}$ Thus, even if undiagnosed, EMP can be satisfactorily managed with hCG surveillance and MTX in cases of hormone elevation. However, these situations are uncommon as EMP that is not diagnosed at an early stage usually progresses to tubal rupture, representing an obstetric emergency.

Finally, we wish to emphasize that this article aims to remind readers of the possibility of ectopic pregnancy being associated with hydatidiform moles. In such cases, patients should be diagnosed early to avoid Fallopian tube rupture and hemoperitoneum. The diagnosis of EMP should be precisely made so as to not lead to overdiagnosis, which causes anxiety and increases the costs of patient care with the introduction of unnecessary hormonal surveillance. ${ }^{13,14}$ Careful postmolar follow-up, identical to that recommended for patients with intrauterine molar pregnancy, should be performed, as there is a risk of EMP progressing to postmolar GTN. These cases should be managed in reference centers for GTD, ${ }^{1,30}$ where routine chemotherapy offers high cure rates and a safe and generally successful reproductive future.

Conflicts to Interest

The authors have no conflicts of interest to declare.

\section{Acknowledgments}

The authors wish to thank Professor Dr. Giovanni Fraga Lenza for the ultrasound images presented in -Figs. 1 and 2.

\section{References}

1 Braga A, Burlá M, Freitas F, et al; Brazilian Network for Gestational Trophoblastic Disease Study Group. Centralized coordination of decentralized assistance for patients with gestational trophoblastic disease in Brazil: a viable strategy for developing countries. J Reprod Med 2016;61(5-6):224-229

2 Lurain JR. Gestational trophoblastic disease I: epidemiology, pathology, clinical presentation and diagnosis of gestational trophoblastic disease, and management of hydatidiform mole. Am J Obstet Gynecol 2010;203(06):531-539 Doi: 10.1016/j.ajog.2010.06.073

3 Seckl MJ, Sebire NJ, Fisher RA, Golfier F, Massuger L, Sessa C; ESMO Guidelines Working Group. Gestational trophoblastic disease: 
ESMO Clinical Practice Guidelines for diagnosis, treatment and follow-up. Ann Oncol 2013;24(Suppl 6):vi39-vi50 Doi: 10.1093/ annonc/mdt345

4 Soares RR, Maestá I, Colón J, et al. Complete molar pregnancy in adolescents from North and South America: Clinical presentation and risk of gestational trophoblastic neoplasia. Gynecol Oncol 2016;142(03):496-500 Doi: 10.1016/j.ygyno.2016.07.002

5 Berkowitz RS, Goldstein DP. Current advances in the management of gestational trophoblastic disease. Gynecol Oncol 2013;128 (01):3-5 Doi: 10.1016/j.ygyno.2012.07.116

6 Biscaro A, Braga A, Berkowitz RS. Diagnosis, classification and treatment of gestational trophoblastic neoplasia. Rev Bras Ginecol Obstet 2015;37(01):42-51 Doi: 10.1590/SO100-720320140005198

7 Braga A, Uberti EM, Fajardo MdoC, et al. Epidemiological report on the treatment of patients with gestational trophoblastic disease in 10 Brazilian referral centers: results after 12 years since International FIGO 2000 Consensus. J Reprod Med 2014;59(5-6): 241-247

8 Chauhan S, Diamond MP, Johns DA. A case of molar ectopic pregnancy. Fertil Steril 2004;81(04):1140-1141 Doi: 10.1016/j. fertnstert.2003.11.022

9 Siozos A, Sriemevan A. A case of true tubal hydatidiform mole and literature review. BMJ Case Rep 2010;2010:bcr0720092123

10 Allen L, Dawson C, Nascu P, Rouse T. A molar pregnancy within the Fallopian tube. Case Rep Obstet Gynecol 2016;2016:4367181

11 Beena D, Teerthanath S, Jose V, Shetty J. Molar pregnancy presents as tubal ectopic pregnancy: a rare case report. J Clin Diagn Res 2016;10(01):ED10-ED11 Doi: 10.7860/JCDR/2016/14875.7089

12 Gillespie AM, Lidbury EA, Tidy JA, Hancock BW. The clinical presentation, treatment, and outcome of patients diagnosed with possible ectopic molar gestation. Int J Gynecol Cancer 2004;14(02):366-369 Doi: 10.1111/j.1048-891X.2004.014223.x

13 Burton JL, Lidbury EA, Gillespie AM, et al. Over-diagnosis of hydatidiform mole in early tubal ectopic pregnancy. Histopathology 2001;38(05):409-417 Doi: 10.1046/j.1365-2559.2001.01151.x

14 Sebire NJ, Lindsay I, Fisher RA, Savage P, Seckl MJ. Overdiagnosis of complete and partial hydatidiform mole in tubal ectopic pregnancies. Int J Gynecol Pathol 2005;24(03):260-264 Doi: 10.1097| 01.pgp.0000164597.19346.b5

15 Yamada Y, Ohira S, Yamazaki T, Shiozawa T. Ectopic molar pregnancy: diagnostic efficacy of magnetic resonance imaging and review of the literature. Case Rep Obstet Gynecol 2016; 2016:7618631

16 Tanha FD, ShirAli E, Rahmanpour H, Haghollahi F. Molar pregnancy presents as tubal ectopic pregnancy. Int J Fertil Steril 2011; 4(04):184-186

17 FIGO Oncology Committee. FIGO staging for gestational trophoblastic neoplasia 2000. Int J Gynaecol Obstet 2002;77(03): 285-287
18 Otto HConcerning Tubal pregnancy with Special Consideration of a Case of Tubal Hydatidiform Mole [inaugural dissertation]. Grunwald; 1871

19 Braga A, Moraes V, Maestá I, et al. Changing trends in the clinical presentation and management of complete hydatidiform mole among Brazilian women. Int J Gynecol Cancer 2016;26(05): 984-990 Doi: 10.1097/IGC.0000000000000682

20 Sebire NJ, Makrydimas G, Agnantis NJ, Zagorianakou N, Rees H, Fisher RA. Updated diagnostic criteria for partial and complete hydatidiform moles in early pregnancy. Anticancer Res 2003;23 (2C):1723-1728

21 LeGallo RD, Stelow EB, Ramirez NC, Atkins KA. Diagnosis of hydatidiform moles using p57 immunohistochemistry and HER2 fluorescent in situ hybridization. Am J Clin Pathol 2008; 129(05):749-755 Doi: 10.1309/7XRL378C22W7APBT

22 Chen Y, Shen D, Gu Y, Zhong P, Xie J, Song Q. The diagnostic value of Ki-67, P53 and P63 in distinguishing partial Hydatidiform mole from hydropic abortion. Wien Klin Wochenschr 2012;124(56):184-187 Doi: 10.1007/s00508-011-0119-4

23 Sarmadi S, Izadi-Mood N, Abbasi A, Sanii S. p57KIP2 immunohistochemical expression: a useful diagnostic tool in discrimination between complete hydatidiform mole and its mimics. Arch Gynecol Obstet 2011;283(04):743-748 Doi: 10.1007/s00404-010-1433-1

24 Hui P, Buza N, Murphy KM, Ronnett BM. Hydatidiform moles: genetic basis and precision diagnosis. Annu Rev Pathol 2017; 12:449-485 Doi: 10.1146/annurev-pathol-052016-100237

25 Cortés-Charry R, Salazar A, García-Barriola V, Dabed P, Figueira LM, Maestá I. Hydatidiform mole in ectopic pregnancy: clinical, imaging, pathological and immunohistochemical characteristics. J Reprod Med 2012;57(7-8):329-332

26 Frates MC, Doubilet PM, Peters HE, Benson CB. Adnexal sonographic findings in ectopic pregnancy and their correlation with tubal rupture and human chorionic gonadotropin levels. J Ultrasound Med 2014;33(04):697-703 Doi: 10.7863/ultra.33.4.697

27 Rocha Filho EA, Santana DS, Cecatti JG, et al. Awareness about a life-threatening condition: ectopic pregnancy in a network for surveillance of severe maternal morbidity in Brazil. BioMed Res Int 2014;2014:965724

28 Lima LL, Parente RC, Maestá I, et al. Clinical and radiological correlations in patients with gestational trophoblastic disease. Radiol Bras 2016;49(04):241-250 Doi: 10.1590/0100-3984.2015.0073

29 Lima LLA, Padron L, Câmara R, Sun SY, Rezende J, Braga A. The role of surgery in the management of women with gestational trophoblastic disease. Rev Col Bras Cir 2017;44(01):94-101 Doi: 10.1590/0100-69912017001009

30 Dantas PR, Maestá I, Cortés-Charry R, et al. Influence of hydatidiform mole follow-up setting on postmolar gestational trophoblastic neoplasia outcomes: a cohort study. J Reprod Med 2012;57 (7-8):305-309 